\title{
Laboreal
}

Volume 15 N² | 2019

Varia

\section{El proceso de reconocimiento de la silicosis como fenómeno social}

\section{Marianne Lacomblez}

\section{(2) OpenEdition}

Journals

Edición electrónica

URL: http://journals.openedition.org/laboreal/15482

DOI: 10.4000/laboreal.15482

ISSN: 1646-5237

Editor

Universidade do Porto

Referencia electrónica

Marianne Lacomblez, «El proceso de reconocimiento de la silicosis como fenómeno social », Laboreal [En línea], Volume 15 №2 | 2019, Publicado el 01 diciembre 2019, consultado el 24 septiembre 2020. URL : http://journals.openedition.org/laboreal/15482 ; DOI : https://doi.org/10.4000/laboreal.15482

Este documento fue generado automáticamente el 24 septiembre 2020.

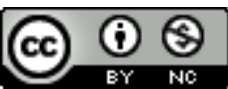

Laboreal está licenciado com uma Licença Creative Commons - Atribuição-NãoComercial 4.0 Internacional. 


\title{
El proceso de reconocimiento de la silicosis como fenómeno social
}

\author{
Marianne Lacomblez
}

1 Tres de las aportaciones publicadas en la Efeméride de este número de Laboreal, describen y analizan tres procesos relativos al reconocimiento médico-legal de la silicosis como enfermedad profesional: tres experiencias nacionales, con sus especialidades y dinámicas históricas propias, en Bélgica, en Brasil y en Portugal.

2 La silicosis fue considerada, en razón del número de víctimas que provocó, como la más grave enfermedad profesional del siglo XX. Pero tal amenaza sigue permaneciendo todavía en este nuevo siglo, en muchos países de diferentes continentes $y$ particularmente en aquellos que son hoy considerados, en el marco del desarrollo económico mundial, países emergentes.

3 El reconocimiento de esta "enfermedad de los polvos" como enfermedad profesional, ha conocido procesos largos y no pocas veces agitados. Tal como lo ilustran los análisis que se presentan a continuación, la cuestión central nunca fue exclusivamente de orden médico-legal, puesto que la reparación de los daños (y su dimensión financiera) implicaba una negociación en la cual lo social, lo económico y lo político tenían, inevitablemente, un papel determinante. De hecho, el desenlace resultará, en general, de dinámicas de enfrentamiento, directo o indirecto, entre los intereses de los empleadores y la salvaguardia de los derechos de los trabajadores.

4 Sin embargo, si el reconocimiento de la silicosis como enfermedad del y en el trabajo constituye una verdadera conquista social, más que imponer la importancia de las políticas de prevención y de mejoría de las condiciones y de la organización del trabajo, acabará con frecuencia por mantener, y quizá reforzar, la idea de su carácter inevitable en el ámbito de una determinada actividad económica. Se trata de cuestiones casi endémicas de la problemática de las enfermedades profesionales, que reencontramos si tenemos en atención lo que sucede con la exposición de numerosos trabajadores a una amplia variedad de productos tóxicos (de los cuales muchos son cancerígenos) y, por ejemplo, a la exposición al amianto - uno de los principales problemas de nuestra contemporaneidad. 
5 En este último caso, el campo de la "salud en el trabajo" se inscribe claramente en el dominio de la "salud pública", realzando, así, uno de los mayores desafíos planteados actualmente a los investigadores y a los actores de la prevención. Deseamos, pues, que la lectura de estos textos enriquezca vuestra reflexión.

\section{AUTOR}

\section{MARIANNE LACOMBLEZ}

Centro de Psicología de la Universidad de Porto, Facultad de Psicología y de Ciencias de la Educación, Universidad de Porto. Rua Alfredo Allen, 4200-135, Porto, Portugal

lacomb@fpce.up.pt 